points, has a fine saw cut about $\frac{3}{4}$ th of an inch deep, made lengthwise at both ends. The wires which form the sides of the first triangle are put into one cut, and those of the second triancle into the other ; and the rod may then be slid up or down along the wires, to different heights, so that when the pendulum is at rest the rod is horizontal, forming the base of one isosceles triangle, with sides of double wire, and its vertex down at the bob, and also of other two isosceles triangles, equal and similar to cne another whose sides are of single wire, and whose vertices are the points of suspension in the ceiling respectively.

It is now evident that the rod is rigorously constrained to oscillate in a piane perpendicular to the line joining the suspension points, while the vertex of the triangle below the rod, which is the point of suspension of the bob, is free to move, at any instant, only in a plane at right angles to the plane of motion of the rod. As the amplitudes of the oscillations are practically made small compared with the lengths of the component pendulums, we thus obtain, with almost any desired degree of exactness, the composition of two simple harmonic motions of different periods of adjustable ratio, and in rectangular directions. It is casy also to see how, by making the wires of unequal. length, and dividing them proportionally at the point of suspension of the bob, the simple component motions may be adjusted to different inclinations. In order absolitely to prevent the bob from creating indeterminate motions about its point of suspension, it would be needful to substitute, for the wires below the suspended rod, stiff pieces rigidly attached to the bob. But with due care in swinging the pendulum no very sensible motion of the bob, relatively to its suspending wires, need occur:

To record the motions of the pendulum, I have most frequently adopted the old plan of sand rmming out at a fine hole at the bottom of the pendulum bob. But for class experiments at the University of St. Andrews, I have also made the following arkangement:-A heavy bob of lead, in metallic connection with its suspending wires, has a metal point projecting from its lower end. Wires from an induction coil are connected, one with either of the suspension points in the ceiling, the other with a sheet of a tin foil which rests on a table, and over which is placed a sheet of paper, all but tonching the point projecting from the bob. The pendulum having been first got to swing steadily, the induction coil is put in action, and the sparks, passing from the pendulum point to the tin foil, trace on the paper, if it be suitably prepared, a record of the pendulum motion. I used one of IRuhmkorff's original coils, which, with a single Grove's cell, was quite sufficient. The rheotome acted automatically, and with considerable regularity. The dots on the paper made by the sparks showed distances varying from one element of the pencluium track to another, and thus exhibited in a very interesting manner the variation in the velocity of the pendulum bob.

Arclchapel, Dumbartonshire, Aug. 24

WILIIAM SWAN

PERMIT me to state that the diagrams in No, 94 of the 17 th June to Mr. Hubert Airy's "Pendnlum Autographs," are identical with the "Kinematic Curves" by Mr. Perigal, drawn by lim upwards of thirty years ago, and discovered by Mr. Sang of E.dinburgh two years previously (On the Vibration of an Elastic Spring, Ed. Ph. Tr.), antographic copies being in the possession of the Royal Society, Reyal Institution, and Royal Astronomical Society. Vide my application of the Binomial Theorem to Terigal's Bicircloins (Lond. Phil. Mag. I 849-1850). Mr: Perigal calls these curves, Lemmoids, Paraboloids, \&c. August 28

S. M. DRACH

\section{Thickness of the Earth's Crust}

Tris question in debate is not a mathematical one. Accepting Archdeacon Pratt's calculations as correct, they would show that certain facts in the earth's motion are what they would be if the earth were a rigid mass, or nearly so. But this at present is not disputed. What is disputed is the soundness of the inference drawn from these facts respecting the fluid or solid state of the earth's interior, for it is contended that in either case the movements in question might be practically the same, provided only they were slow enough. I do not think this is replied to by Archdeacon Pratt in his letter in Nature, August 3I.

Whatever the disturbing forces may be, they amount to a motive impulse given to some portion of the mass of the eartli.
This impulse may have two effects : either it may alter the shape of the mass by causing part of it to move in some clirection faster than the rest can follow, or it may alter the position of the mass by causing the whole to move together. If the portion which receives the impulse is able to move the rest as quickly as it moves itself, the whole will move together; and where there is any cohesion at all, there must be a degree of slowness at which this condition is attained.

Mr. Pratt's rope of sand, if dealt with here, is a system of particles between which there is no cohesion. They are not able, by attractive power, to move each other at all. But if hung out in free space, they would certainly assume a definite shape as a whole, and would retain it with complete "rigidity" in spite of any applied force which was not able to move any of them faster than they could move each other.

Suppose the earth were projected bodily along the line of its axis towards the pole star, what would happen to a loose stone lying on the surface at the south pole? If the earth moved northward ten feet in a second, the stone would, at the end of the first second, be still upon the surface. If the earth moved twenty feet in a second, the stone, at the end of the first second, would be a yard behind it, but before the end of the next second it would be on the surface aguin. Are not the relations between the rigid, the fluid, and the elastic states all illustrated here? What would be the real colnesive force in a molten earth, as compared with a congealed one, is another matter. "Molten" does not neccssarily mean "limp," and the question, if deter. minable, bas not, I imagine, been determined. The molten earth would no doubt be less compressible; and this, in some cases, may be equivalent to an increased cohesion. Let me add that I have no theory as to the earth's interior. A. J. M.

Sept. 5

\section{Spectrum of the Aurora}

MAY I call your attention to an error which has occurred in the engraving of the Spectrum of the Aurora which I sent you last week. The lines are marked in strength exactly the reverse of what they should be. Thus: No. I is the strongest, and is a sharp line easily seen, and in the drawing it is the weakest; and so with the others. No. I is the brightest, No, 5 is the faintest. 47 , Brook Street

LINDSAY

\section{Transparent Compass}

I BEG leave to draw your attention to a contrivance that I think very suggestive, of improvements in getting up compasses for iron and wooden vessels. This I propose to effect by using glass globes with transparent needle-cards, and thus making a transparent mariner's compass, visible in all directions, that may be either supported or suspended by very simple and compact fittings wherever most convenient.

In iron vessels this transparent compass can be readily placed beyond the local attraction of the iron. In appearance Jike a pearl, and in good taste.

Please draw attention to this very simple remedy for so many real or alleged complaints of the deviation of the compass on board of iron vessels.

North Shields, Sept. 4

George FawCús

\section{A Substitute for Euclid}

SINCE Prof. Tait has given the weight of his authority to the atlack for some time past directed against Euclid, I, and perhaps some others who like me have sons whom they wish to educate as mathematicians, would be much obliged to $\mathrm{Mr}$. Wilson, or any other of your correspondents, who would recommenci a book which is stited to lay the foundation of geometry in the future.

A FATHER

\section{Monolithic Towers of Cement Rubble for Beacons and Lighthouses}

IT occurs to me to suggest the trial of common rubble set in Portland or other equally good cement in the construction of beacons and seamarks, as also for lighthouses. The advantages of employing cement rubble, not in prepared blocks but by continuous building, are the following :-

$x$. The dispensing with all squaring or dressing of materials.

2. The suitableness for such work of any stone of hard guality thus rendering it unnecessary to bring large materials from a distance, or to open quarries for ashlar. 